\title{
Effect of dietary $\alpha$-lipoic acid on the mRNA expression of genes involved in drug metabolism and antioxidation system in rat liver
}

\author{
Takashi Ide*† \\ Laboratory of Nutritional Function, National Food Research Institute, 2-1-12 Kannondai, Tsukuba 305-8642, Japan
}

(Submitted 30 July 2013 - Final revision received 11 March 2014-Accepted 20 March 2014 - First published online 1 May 2014)

\section{Abstract}

In the present study, the mRNA levels of hepatic proteins involved in the drug metabolism of rats fed $\alpha$-lipoic acid were evaluated by DNA microarray and real-time PCR analyses. Experimental diets containing $0,0 \cdot 1,0.25$ and $0.5 \%(\mathrm{w} / \mathrm{w}) \alpha$-lipoic acid were fed to four groups of rats consisting of seven animals each for $21 \mathrm{~d}$. DNA microarray analysis revealed that the diet containing $0.5 \% \alpha$-lipoic acid significantly $(P<0.05)$ increased the mRNA levels of various phase I drug-metabolising enzymes up to 15 -fold and phase II enzymes up to 52 -fold in an isoenzyme-specific manner. $\alpha$-Lipoic acid also up-regulated the mRNA levels of some members of the ATP-binding cassette transporter superfamily, presumed to be involved in the exportation of xenobiotics, up to 6.6-fold. In addition, we observed that $\alpha$-lipoic acid increased the mRNA levels of many proteins involved in antioxidation, such as members of the thiol redox system (up to $5 \cdot 5$-fold), metallothioneins (up to 12 -fold) and haeme oxygenase 1 (1.5-fold). These results were confirmed using real-time PCR analysis, and $\alpha$-lipoic acid dose dependently increased the mRNA levels of various proteins involved in drug metabolism and antioxidation. Consistent with these observations, $\alpha$-lipoic acid dose dependently increased the hepatic concentration of glutathione and the activities of glutathione reductase and glutathione transferase measured using 1-chloro-2,4-dinitrobenzene and 1,2-dichloro-4-nitrobenzene as substrates, but decreased the hepatic and serum concentrations of malondialdehyde. In conclusion, the present study unequivocally demonstrated that $\alpha$-lipoic acid increases the mRNA expression of proteins involved in drug metabolism and antioxidation in the liver.

Key words: $\boldsymbol{\alpha}$-Lipoic acid: DNA microarrays: Drug metabolism: Antioxidation

$\alpha$-Lipoic acid is a natural compound that is widely distributed in plants and animals and functions as a cofactor within mitochondrial enzymes to catalyse the oxidative decarboxylation of $\alpha$-keto acids (such as pyruvate dehydrogenase and $\alpha$-ketoglutarate dehydrogenase) and the cleavage of glycine ${ }^{(1,2)}$. Besides its role in the mitochondrial metabolic pathway, $\alpha$-lipoic acid, when supplemented in diets, performs various physiological activities in experimental animals ${ }^{(1,2)}$ and is widely used as a dietary supplement by humans. However, the concentration of $\alpha$-lipoic acid in natural food items is very low ${ }^{(3)}$. Therefore, dietary $\alpha$-lipoic acid supplements are manufactured by chemical synthesis. It has been well established that dietary $\alpha$-lipoic acid is effective at attenuating oxidative stress $^{(1,2,4-8)}$. Many studies have also indicated that $\alpha$-lipoic acid modulates glucose metabolism and is effective at ameliorating insulin resistance and attenuating type 2 diabetes $^{(1,6,7)}$. The lipid-lowering property of $\alpha$-lipoic acid has also frequently been reported ${ }^{(2,9-11)}$. In this context, we had previously demonstrated that $\alpha$-lipoic acid strongly reduces the activity and mRNA levels of hepatic lipogenic enzymes in rats ${ }^{(12-14)}$. Therefore, the reduction in hepatic lipid biosynthesis may account for the lipid-lowering effect of $\alpha$-lipoic acid. During the course of the studies, we had found that dietary $\alpha$-lipoic acid lowers serum concentrations of TAG, cholesterol and phospholipids and hepatic concentrations of TAG and cholesterol, but increases the hepatic concentration of phospholipids. The increased hepatic concentration of phospholipids implies that $\alpha$-lipoic acid causes biomembrane proliferation in this tissue. We hypothesise that $\alpha$-lipoic acid is an inducer of hepatic drug-metabolising enzymes because drugs

Abbreviations: $A b c$, ATP-binding cassette; $A k r$, aldo-keto reductase; Aldh, aldehyde dehydrogenase; Apex1, APEX nuclease 1; Ces $2 c$, carboxylesterase 2C; Cyp, cytochrome P450; Ephx1, epoxide hydrolase 1, microsomal; Fmo, flavin-containing monooxygenase; Gclc, glutamate-cysteine ligase, catalytic subunit; Gclm, glutamate-cysteine ligase, modifier subunit; Glrx, glutaredoxin; Gpx, glutathione peroxidase; Gs $r$, glutathione reductase; Gst, glutathione transferase; Hmox, haeme oxygenase; $M t$, metallothionein; NOAEL, no observed adverse effect level; Nqo1, NAD(P)H dehydrogenase, quinone 1; Nr1i3, nuclear receptor subfamily 1, group I, member 3; Nrf2, NFE2-related factor 2; Srxn1, sulfiredoxin 1; Sult, sulfotransferase family, cytosolic; Txnrd1, thioredoxin reductase 1; Ugt, UDP-glucuronosyltransferase.

*Corresponding author: T. Ide, fax +81 484789367 , email t-ide@jumonji-u.ac.jp

† Present address: Department of Food and Nutrition, Faculty of Human Life, Jumonji University, 2-1-28 Sugasawa, Niiza, Saitama 352-8510, Japan. 
that induce hepatic drug metabolism also increase phospholipid concentration and synthesis in this tissue accompanying the proliferation of the endoplasmic reticulum ${ }^{(15)}$. In relation to this, some studies ${ }^{(16-18)}$ have shown that $\alpha$-lipoic acid increases the mRNA expression or activity or the protein concentrations of drug-metabolising enzymes in cultured cells. However, information on the effect of $\alpha$-lipoic acid on drugmetabolising enzymes in experimental animals is lacking. In this context, we investigated the effect of dietary $\alpha$-lipoic acid on the gene expression of hepatic enzymes involved in drug metabolism in rats in the present study, employing DNA microarray analysis, a powerful technique for analysing the mRNA expression of thousands of genes in a short period of time. Drug metabolism usually involves many isoenzymes differing in substrate specificity. A considerable number of isoenzymes are relatively irrelevant and only a small number are sensitive to dietary factors ${ }^{(19)}$. Therefore, microarray-based profiling of gene expression helps to clarify the overall picture of the physiological effect of $\alpha$-lipoic acid on the mRNA expression of enzymes involved in drug metabolism and to identify isoenzyme(s) specifically affected by this compound.

\section{Materials and methods}

\section{Animals and diets}

Male Sprague-Dawley rats obtained from Charles River Japan at 4 weeks of age were housed individually in animal cages in a room with controlled temperature $\left(20-22^{\circ} \mathrm{C}\right)$, humidity $(55-$ $65 \%$ ) and lighting (lights on from 07.00 to 19.00 hours) and fed a commercial non-purified diet (Type NMF; Oriental Yeast Company) for $7 \mathrm{~d}$. After this acclimatisation period, the rats were randomly divided into four groups with equal mean body weights, consisting of seven animals each, and fed purified experimental diets containing $0,0 \cdot 1,0.25$ and $0.5 \%(\mathrm{w} / \mathrm{w})$ of $\mathrm{R} / \mathrm{S}-\alpha$-lipoic acid for $21 \mathrm{~d}$. Rats are widely used as an animal model for humans to evaluate the physiological activity of dietary factors. The basal composition of the experimental diets was as follows (in $\mathrm{wt} \%$ ): palm oil, 10; casein, 20; maize starch, 15; cellulose, 2; mineral mixture $(\mathrm{AIN}-93 \mathrm{G}-\mathrm{MX})^{(20)}, 3 \cdot 5$; vitamin mixture $(\mathrm{AIN}-93-\mathrm{VX})^{(20)}, 1 \cdot 0$; L-cystine, 0.3; choline bitartrate, 0.25; sucrose, $100 \mathrm{~g}$. There were $15 \mathrm{~g}$ of DL- $\alpha$-tocopherol acetate in $1 \mathrm{~kg}$ of AIN-93-VX. HPLC analysis revealed that $1 \mathrm{~kg}$ of palm oil contained $0.164 \mathrm{~g}$ of $\mathrm{D}$ - $\alpha$-tocopherol and $0.0059 \mathrm{~g}$ of $\mathrm{D}$ - $\boldsymbol{\gamma}$-tocopherol. Therefore, all the experimental diets contained $0 \cdot 015 \%(\mathrm{w} / \mathrm{w})$ DL- $\alpha$-tocopherol acetate, $0.016 \%(\mathrm{w} / \mathrm{w}) \mathrm{D}-\alpha$-tocopherol and $0.0006 \%(\mathrm{w} / \mathrm{w}) \mathrm{D}-\boldsymbol{\gamma}$-tocopherol as antioxidants. Although the AIN-93G diet formula recommended by the American Institute of Nutrition ${ }^{(20)}$ is suggested to provide $0.0014 \%(\mathrm{w} / \mathrm{w})$ tert-butylhydroquinone as an antioxidant, we did not use this compound in the present study. Chemically synthesised R/S- $\alpha$-lipoic acid with purity exceeding $990 \mathrm{~g} / \mathrm{kg}$ (manufacturer's statement) was purchased from Tokyo Chemical Industry. Enantioselective HPLC analysis ${ }^{(21)}$ using 11-mercaptoundecanoic acid as an internal standard revealed that the $\mathrm{R} / \mathrm{S}$ - $\alpha$-lipoic acid preparation contained 45.9 and
$54 \cdot 1 \%(\mathrm{w} / \mathrm{w})$ of $\mathrm{R}$-isomers and S-isomers, respectively. Varying amounts of $\alpha$-lipoic acid were added to the diets at the expense of sucrose. This resulted in a decrease in the energy content of the experimental diets. However, this decrease was very small (less than $0.23 \%$ of the total energy of the diets). Upon completion of the experimental period, the rats were anaesthetised using diethyl ether and killed by bleeding from the abdominal aorta, after which the livers were excised. The present study was approved by the review board of animal ethics of our institute, and we followed the institute's guidelines in the care and use of laboratory animals. We read and followed the ARRIVE (Animal Research: Reporting In Vivo Experiments) guidelines for animal research (http://www.nc3rs.org.uk/page.asp?id = 1357) in conducting the animal experiment and in preparing the manuscript.

\section{Affymetrix GeneChip and GeneSpring analyses}

Hepatic RNA was extracted according to the method of Chomczynski \& Sacchi ${ }^{(22)}$. RNA from the livers of six rats fed diets containing 0 and $0.5 \%(\mathrm{w} / \mathrm{w}) \alpha$-lipoic acid each was subjected to microarray analyses. Rats with the lowest body weights in each group at the time of killing were excluded from the microarray analyses. RNA was processed using kits supplied by Affymetrix to prepare fragmented biotinylated complementary RNA for hybridisation to the Rat Genome 2302.0 Array. DNA microarray data were analysed using the GeneSpring GX version 7.3 software (Agilent Technologies, Inc.). Normalisations per chip and per gene were carried out using the 50th percentile value of signal intensity in each chip and the mean values in rats fed a control diet free of $\alpha$-lipoic acid, respectively. After normalisation, the following filtering criteria were adopted to prepare the gene list for subsequent analysis to eliminate unreliable data with low signals: the expression data had to call more than six P- or M-flags according to the Affymetrix algorithm out of twelve measurements and the average signal intensity had to be greater than 100 in each treatment. The expression data of 12335 genes fulfilled these criteria. Fold changes in the expression of genes in rats fed the diet containing $0.5 \%(\mathrm{w} / \mathrm{w}) \quad \alpha$-lipoic acid compared with the values in rats fed the diet free of this compound were evaluated using this gene list.

\section{Real-time PCR quantification of $M R N A$}

The real-time PCR quantification of mRNA was carried out as described previously ${ }^{(23)}$ in rats fed diets containing $0,0 \cdot 1$, 0.25 and $0.5 \%(\mathrm{w} / \mathrm{w}) \quad \alpha$-lipoic acid. The abundance of mRNA was calculated as a ratio to the abundance of $\beta$-actin mRNA in each complementary DNA sample and expressed as a fold change, assigning a value of 1 for rats fed the diet free of $\alpha$-lipoic acid. The mRNA levels of the aldehyde dehydrogenase 1 family, member A1 (Aldb1a1), aldo-keto reductase family 1 , member D1 ( $A k r 1 d 1)$, aldo-keto reductase family 7, member A3 (Akr7a3), cytochrome P450, family 2, subfamily b, polypeptide 12 (Cyp2b12), cytochrome P450, family 4 , subfamily b, polypeptide 1 ( $C y p 4 b 1$ ), epoxide hydrolase 1, microsomal (Ephx1), flavin-containing monooxygenase 
5 (Fmo5), glutamate-cysteine ligase, modifier subunit ( $\mathrm{Glm}$ ), glutamate-cysteine ligase, catalytic subunit ( $G c l c)$, glutathione reductase (Gsr), glutathione $S$-transferase alpha 3 (Gsta3), glutathione $S$-transferase pi 1 (Gstp1), glutathione $S$-transferase theta 1 (Gstt1), glutathione $S$-transferase theta 3 (Gstt3), metallothionein 1a (Mt1a) and NAD(P)H dehydrogenase, quinone 1 (Nqo1) were measured using the TaqMan probe PCR method as described in the handbook (Real-time PCR Systems Chemistry Guide) supplied by Applied Biosystems. The nucleotide sequences of primers and probes used for detecting these mRNA were designed using the Primer Express Software (Applied Biosystems), and these are listed in Table 1. The mRNA levels of the ATP-binding cassette, subfamily B, member 1A $(A b c b 1 a)$, ATP-binding cassette, subfamily C, member 4 (Abcc4), carboxylesterase 2C (Ces2c), glutathione peroxidase 2 (Gpx2), nuclear receptor subfamily 1, group I, member 3 (Nr1i3), sulfotransferase family, cytosolic, 1C, member 2 (Sult1c2) and UDP-glucuronosyltransferase 2 family, polypeptide B1 (Ugt2b1) were measured using the SYBR Green PCR method. Forward and reverse primers used for detecting these mRNA were designed, prepared and provided by Takara Bio, Inc. The reaction specificity for this method was verified by a melting curve analysis. The nucleotide sequences of primers are also listed in Table 1.

\section{Enzyme assays}

About $2.5 \mathrm{~g}$ of each liver sample were homogenised with $15 \mathrm{ml}$ of $0.25 \mathrm{~m}$-sucrose containing $1 \mathrm{~mm}$-EDTA and $3 \mathrm{~mm}$-Tris- $\mathrm{HCl}$ $(\mathrm{pH} 7 \cdot 2)$ and centrifuged at $200000 \boldsymbol{g}$ for $30 \mathrm{~min}$. The activities of Gst and Gsr were measured spectrophotometrically using $200000 \mathrm{~g}$ supernatant as an enzyme source. The activity of Gst was assayed using 1-chloro-2,4-dinitrobenzene, 1,2dichloro-4-nitrobenzene, p-nitrobenzyl chloride and ethacrynic acid as substrates. The respective conditions (concentrations of substrates and $\mathrm{pH}$ ) under which enzyme activity was determined using these substrates were the same as those described by Habig \& Jakoby ${ }^{(24)}$. The activity of Gsr was measured according to the method described by Carlberg \& Mannervik ${ }^{(25)}$.

\section{Analyses of serum and liver components}

For the determination of hepatic glutathione concentration, about $1.5 \mathrm{~g}$ of liver sample were homogenised with $4.5 \mathrm{ml}$ of $8 \%$ perchloric acid and centrifuged at $15000 \mathrm{~g}$ for $30 \mathrm{~min}$. The supernatants ( $4 \mathrm{ml}$ each) were neutralised with $3 \mathrm{M}$ $\mathrm{K}_{2} \mathrm{CO}_{3}$. After allowing to stand in ice for $10 \mathrm{~min}$, the mixtures were centrifuged at $3000 \mathrm{~g}$ for $10 \mathrm{~min}$. The supernatants were used to determine glutathione concentration by the method of Anderson ${ }^{(26)}$. Malondialdehyde in the serum and liver samples was analysed by HPLC as thiobarbituric acid adducts ${ }^{(27)}$.

\section{Statistical analysis}

Microsoft Excel add-in software (Excel Statistics 2010, Social Survey Research Information Company) was used for statistical analysis. The constancy of the variance and normality of the distribution of the observations were evaluated using Levene's test and the Kolmogorov-Smirnov test, respectively. If variances were heterogeneous and/or the distributions were not normal, they were transformed logarithmically. The transformations were successful in rendering the variance of the observation constant and the distribution of data normal, and hence the transformed values were used for subsequent statistical evaluations. Significant differences in the means for microarray data at a level of $P<0.05$ were evaluated with two-sided Student's $t$ test. The other data were analysed with one-way ANOVA to establish whether the effect of $\alpha$-lipoic acid was significant, and significant differences in the means at a level of $P<0.05$ were evaluated with twosided Tukey's test.

\section{Results}

\section{Growth parameters and liver weight}

$\alpha$-Lipoic acid at a dietary level of up to $0.25 \%(\mathrm{w} / \mathrm{w}) \mathrm{did}$ not affect food intake (Table 2). However, the diet containing $0.5 \%(\mathrm{w} / \mathrm{w}) \alpha$-lipoic acid compared with the diet free of this compound significantly reduced this parameter. Growth was significantly lower in rats fed diets containing 0.25 and $0.5 \%$ (w/w) $\alpha$-lipoic acid than in those fed the $\alpha$-lipoic acid-free diet. The diet containing $0 \cdot 1 \%(\mathrm{w} / \mathrm{w}) \alpha$-lipoic acid did not affect this parameter. Liver weights were the same among rats fed diets containing $0,0 \cdot 1$ and $0.25 \%(\mathrm{w} / \mathrm{w}) \alpha$-lipoic acid. However, this parameter was significantly higher in rats fed the diet containing $0.5 \%(\mathrm{w} / \mathrm{w}) \alpha$-lipoic acid than in those fed the $\alpha$-lipoic acid-free diet.

\section{Microarray analysis of mRNA expression}

Considerable numbers of genes were affected by dietary $\alpha$ lipoic acid. In total, 997 and 1074 of the 12335 filtered genes were found to be up-regulated and down-regulated, respectively, more than 1.5 -fold by the diet containing $0.5 \%$ $(\mathrm{w} / \mathrm{w}) \alpha$-lipoic acid. The numbers of genes up-regulated and down-regulated more than 2 -fold by $\alpha$-lipoic acid were 410 and 245 , respectively. We had previously reported that $\alpha$-lipoic acid reduces the activity and mRNA levels of many enzymes involved in lipogenesis in the liver ${ }^{(12-14)}$. Consistent with this observation, in the present study using DNA microarray analysis, we observed that $\alpha$-lipoic acid down-regulated many genes related to lipogenesis more than 1.5-fold. These included the patatin-like phospholipase domain containing 3 (Pnpla3; four probes detected the mRNA levels of this protein and the values assigning a value of 1 for rats fed the diet free of $\alpha$-lipoic acid were in the range of 0.052-0.081), fatty acid synthase (Fasn; the values for two probes were 0.125 and 0.251), acetyl-CoA carboxylase- $\alpha$ and $-\beta$ (Acaca and Acacb; the values for two probes were 0.350 and 0.438 and 0.166 and $0 \cdot 188$, respectively), ELOVL fatty acid elongase-2, -5 and -6 (Elovl2, -5 and $-6 ; 0.337$ and 0.505 for Elovl2 and -5, respectively, and $0 \cdot 213$ and $0 \cdot 250$ for Elovl 6 for two probes, respectively), pyruvate kinase, liver and red blood cell (Pklr; 0.351), thyroid hormone-responsive protein (Thrsp; 0.383 and 0.506 
Table 1. Primers and probes used in real-time PCR analysis of mRNA

\begin{tabular}{|c|c|c|c|c|c|}
\hline Genes (gene symbol) & Sense primer & Antisense primer & Probe & $\begin{array}{l}\text { Length } \\
\text { of PCR } \\
\text { products } \\
\text { (bp) }\end{array}$ & $\begin{array}{l}\text { GenBank } \\
\text { accession } \\
\text { no. } \\
\end{array}$ \\
\hline \multicolumn{6}{|l|}{ TaqMan probe PCR method } \\
\hline $\begin{array}{l}\text { Aldehyde dehydrogenase } 1 \\
\text { family, member A1 (Aldh1a1) }\end{array}$ & 5'-GGAGGACCAGTCGTGATTTAAGC-3' & 5'-CCGACTCTGCAGTTATCATGCA-3' & 5'-TGTCCCTCTGTGACCCCTTGAACTGCT-3' & 82 & NM_022407 \\
\hline $\begin{array}{l}\text { Aldo-keto reductase family } 1 \text {, } \\
\text { member D1 (Akr1d1) }\end{array}$ & $5^{\prime}$-CACCACATACCCCTAAATGATGGT-3' & 5'-CCGGTCTAGGGTCTGAGTAGGTT-3' & 5'-ACAGCATTCCGATCATCGGGCTTG-3' & 73 & NM_138884 \\
\hline $\begin{array}{l}\text { Aldo-keto reductase family } 7 \text {, } \\
\text { member A3 (Akr7a3) }\end{array}$ & 5'-GGTTCTTTCCTTTTTTAGACAGGTCACT-3' & 5'-CTCAGCCAGCTCTCACTTTGAA-3' & 5'-TTTCTTCCCTGCTTTCTATACAGCCAGTTGC-3' & 86 & NM_013215 \\
\hline $\begin{array}{l}\text { Cytochrome P450, family } 2 \text {, } \\
\text { subfamily b, polypeptide } 12 \\
\text { (Cyp2b12) }\end{array}$ & 5'-GAACAAAATTATGCTGTGAGTCTAGAAGA- $3^{\prime}$ & 5'-CAGCTTCGTTATATGAATTTCATCTGA-3' & 5'-CAACCCССTCTCCTGCTTCTGTTTCA-3' & 85 & NM_017156 \\
\hline $\begin{array}{l}\text { Cytochrome P450, family } 4 \text {, } \\
\text { subfamily b, polypeptide } 1 \\
\text { (Cyp4b1) }\end{array}$ & 5'-GGCCAGGGCTATGGACAGTT-3' & $5^{\prime}$-ATCTCAAGGGCATGACCAAAA- $3^{\prime}$ & $5^{\prime}$-CCCAGGGCCCCCCACACA-3' & 66 & NM_016999 \\
\hline $\begin{array}{l}\text { Epoxide hydrolase 1, } \\
\text { microsomal (Ephx1) }\end{array}$ & 5'-GAGTTTTACAAGATCATCCCACTACTGA-3' & $5^{\prime}$-TTCAAACACGTGCTCGTCACT-3' & $5^{\prime}$-TGACCCCAAGTCCCACGGTCT- $3^{\prime}$ & 72 & NM_001034090 \\
\hline $\begin{array}{l}\text { Flavin-containing mono- } \\
\text { oxygenase } 5 \text { (Fmo5) }\end{array}$ & 5'-TGGGAGCCATTATGCCTATTTC- $3^{\prime}$ & $5^{\prime}$-GGCAATTTCTTTAGCCCTTTGA- $3^{\prime}$ & 5'-AGCTCCAAGGACGCTGGGCCACT-3' & 76 & NM_144739 \\
\hline $\begin{array}{l}\text { Glu-Cys ligase, modifier } \\
\text { subunit }(G C l m)\end{array}$ & 5'-CGCCTGCGGAAAAAGTGT-3' & 5'-TCATTCAAGGTCTTTTGGATACAGTCT-3' & 5'-CGTCCACGCACAGCGAGGAGCT-3' & 71 & NM_017305 \\
\hline $\begin{array}{l}\text { Glu-Cys ligase, catalytic } \\
\text { subunit }(G / l) \text { ) }\end{array}$ & 5'-AACATCAGGCTCTTTGCACGAT-3' & $5^{\prime}$-TGCTCTGGCAGTGTGAATCC-3' & 5'-CTTCATTTCCCAGGCTAGGCTGCCC- $3^{\prime}$ & 70 & NM_012815 \\
\hline Glutathione reductase (Gsr) & 5'-AACATCCCTACCGTGGTCTTCA-3' & 5'-GGACGGCTTCATCTTCAGTGA-3' & 5'-CACCCGCCTATCGGGACAGTGG-3' & 70 & NM_053906 \\
\hline $\begin{array}{l}\text { Glutathione S-transferase } \\
\text { alpha } 3 \text { (Gsta3) }\end{array}$ & 5'-TAAAGGCCCTGAGAACCAGAGT-3' & 5'-TGGCTGCCAGGCTGAAG-3' & 5'-AGCAACCTCCCCACAGTGAAGAAATT- $3^{\prime}$ & 67 & NM_001009920 \\
\hline $\begin{array}{l}\text { Glutathione } S \text {-transferase pi } 1 \\
\text { (Gstp1) }\end{array}$ & 5'-GGAGGAGGTGGTTACCATAGATGT-3' & $5^{\prime}$-GGAGCTGCCCATACAGACAAG-3' & 5'-TGGCTTCAAGGCTCGCTCAAGTCC-3' & 71 & NM_012577 \\
\hline $\begin{array}{l}\text { Glutathione } S \text {-transferase } \\
\text { theta } 1 \text { (Gstt1) }\end{array}$ & 5'-CCGTGCTCGTGTGGATGAG-3' & $5^{\prime}$-CAGGGTCCGGAGACAGCTT-3' & $5^{\prime}$-TGGCATGGCAGCATACGACCCTTC- $3^{\prime}$ & 70 & NM_053293. \\
\hline $\begin{array}{l}\text { Glutathione } S \text {-transferase } \\
\text { theta } 3 \text { (Gstt3) }\end{array}$ & $5^{\prime}$-TGCAAGGGCAGTCACGAA-3' & 5'-GCCTTTGTCCTCAGGGTCTTC-3' & 5'-AGCCCTGCACCCCACCTATACCA-3' & 70 & ВМ390378 \\
\hline Metallothionein 1a (Mt1a) & $5^{\prime}$-TGTGCCTGAAGTGACGAACAG- $3^{\prime}$ & 5'-AGGTGTACGGCAAGACTCTGAGT-3' & $5^{\prime}$-TGCCCTCAGGTGTAAATAATTTCCGGACC- $3^{\prime}$ & 80 & NM_138826 \\
\hline $\begin{array}{l}\mathrm{NAD}(\mathrm{P}) \mathrm{H} \text { dehydrogenase, } \\
\text { quinone } 1 \text { (Nq01) }\end{array}$ & $5^{\prime}$-GCCGAAGGACTCGGAGAAC- $3^{\prime}$ & 5'-CTCAGGCGGCCTTCCTTATA-3' & 5'-TTCAGTACCCTGTTGAGTCATCTCTG-3' & 69 & NM_017000 \\
\hline $\begin{array}{l}\text { Thioredoxin reductase } 1 \\
\text { (Txnrd1) }\end{array}$ & $5^{\prime}$-TTTGACAAGAAGGTGATGGTCTTG-3' & $5^{\prime}$-CCCCCGAGACCCCATCT- $3^{\prime}$ & 5'-ACTTCGTCACACCAACTCCTCTCGGAAC-3' & 71 & NM_031614 \\
\hline \multicolumn{6}{|l|}{ SYBR Green PCR method } \\
\hline $\begin{array}{l}\text { ATP-binding cassette, sub- } \\
\text { family B, member } 1 \mathrm{~A} \\
\text { (Abcb1a) }\end{array}$ & 5'-AGATCGTGAAGGCAGCCAAG-3' & 5'-AGAAGTAAGATGTGAGGCTGTCTGA-3' & & 166 & NM_133401.1 \\
\hline $\begin{array}{l}\text { ATP-binding cassette, sub- } \\
\text { family } C \text {, member } 4 \text { ( } A b c c 4)\end{array}$ & 5'-AGCCCTGCGGTTATGAGCAC-3' & $5^{\prime}$-GGACACCCTGGAAACAGACTTGA-3' & & 106 & NM_133411.1 \\
\hline Carboxylesterase 2C (Ces2c) & 5'-AGCTGCTGAGTAGGCGGATGA-3' & $5^{\prime}$-CCAACACAGGCCAGTAGGGTAGA-3' & & 93 & NM_133586.1 \\
\hline $\begin{array}{l}\text { Glutathione peroxidase } 2 \\
\text { (Gpx2) }\end{array}$ & $5^{\prime}$-TGAGTTGCAGTGCCGCTTTC-3' & 5'-GGACATACTTGAGGCTGTTCAGGA-3' & & 116 & NM_183403.2 \\
\hline $\begin{array}{l}\text { Nuclear receptor subfamily } 1 \text {, } \\
\text { group I, member } 3 \text { (Nr1i3) }\end{array}$ & 5'-ATGGAGCAACAGTCAAGACTCCAA-3' & 5'-CCCTGGATGCGATGGATTTC-3' & & 116 & NM_022941.3 \\
\hline $\begin{array}{l}\text { Sulfotransferase family, } \\
\text { cytosolic, 1C, member } 2 \\
\text { (Sult1c2) }\end{array}$ & 5'-ACATGAAGGTGGCCTTTGGAA-3' & 5'-AACTGGCTCCACACTGACCATC-3' & & 81 & NM_133547.4 \\
\hline $\begin{array}{l}\text { UDP-glucuronosyltransferase } \\
2 \text { family, polypeptide B1 } \\
\text { (Ugt2b1) }\end{array}$ & 5'-GCTTCTGCTCTTGCCCAAATTC-3' & 5'-GCCTCATAGATGCCATTTGTTCC-3' & & 176 & NM_173295.1 \\
\hline
\end{tabular}


Table 2. Growth parameters and liver weight

(Mean values with their standard errors, $n 7$ )

\begin{tabular}{|c|c|c|c|c|c|c|c|c|}
\hline & \multicolumn{8}{|c|}{ Dietary $\alpha$-lipoic acid (wt\%) } \\
\hline & \multicolumn{2}{|c|}{0} & \multicolumn{2}{|c|}{$0 \cdot 1$} & \multicolumn{2}{|c|}{0.25} & \multicolumn{2}{|c|}{0.5} \\
\hline & Mean & SEM & Mean & SEM & Mean & SEM & Mean & SEM \\
\hline \multicolumn{9}{|l|}{ Body weight } \\
\hline Initial (g) & 136 & 3 & 135 & 2 & 135 & 2 & 138 & 2 \\
\hline Final $(\mathrm{g})$ & 309 & 9 & 297 & 10 & $274^{\star}$ & 7 & $260^{\star \star}$ & 7 \\
\hline Growth (g/21 d) & 173 & 8 & 162 & 10 & $139^{\star}$ & 9 & $122^{\star *}$ & 7 \\
\hline Food intake $(\mathrm{g} / \mathrm{d})$ & 19.5 & 0.8 & $18 \cdot 7$ & 0.8 & $17 \cdot 8$ & 0.2 & $15 \cdot 9^{\star *}$ & 0.4 \\
\hline Liver weight ( $\mathrm{g} / 100 \mathrm{~g}$ body weight) & $5 \cdot 15$ & 0.27 & 4.98 & 0.16 & 5.06 & 0.18 & $5 \cdot 86^{*}$ & 0.12 \\
\hline
\end{tabular}

Mean values were significantly different from those of rats fed the $\alpha$-lipoic acid-free diet: ${ }^{\star} P<0.05 ;{ }^{\star *} P<0.01$.

for two probes), phosphogluconate dehydrogenase (Pgd; 0.403), stearoyl-CoA desaturase 1 ( $S c d 1 ; 0.458)$, glycerol3-phosphate acyltransferase, mitochondrial (Gpam; 0.467 and 0.619 for two probes), glucose-6-phosphate dehydrogenase (GGpd; 0.504), ATP citrate lyase (Acly; 0.519 and 0.532 for two probes), fatty acid desaturase-1 and -2 (Fads1 and -2; 0.566 and 0.541 , respectively), malic enzyme 1 (Me1; 0.561 and 0.600 for two probes) and SREBF chaperone (Scap; 0.575).

In addition to the lipogenic pathway, we found that genes involved in drug metabolism and the antioxidation system were targeted by dietary $\alpha$-lipoic acid. Table 3 lists the genes affected more than 1.5 -fold by the diet containing $0.5 \%(\mathrm{w} / \mathrm{w}) \alpha$-lipoic acid. The drug metabolism pathway has generally been grouped into phase I reactions, in which enzymes carry out oxidation, reduction or hydrolysis reactions; phase II reactions, in which enzymes form a conjugate of the substrate; and phase III reactions, in which enzymes transport drugs. $\alpha$-Lipoic acid apparently increased the mRNA expression of many phase I enzymes that catalyse oxidation (Cyp4b1, Cyp2b12 and Fmo5), reduction (Akr7a3, Aldb18a1, Aldb1a7, Akr1c1, Aldb1a1, Akr1d1 and Nqo1) and hydrolysis reactions (Ces2c and Ephx1). This compound also increased mRNA expressions of phase II enzymes that catalyse glutathione conjugation (Gsta3, Gstt3, Gstp1, Gstt1 and Gsto1), sulfation (Sult1c2) and glucuronidation (Ugt2b1 and Ugt1a). The mRNA expression of some phase III transporters, including $A b c b 1 a$, ATP-binding cassette, subfamily B, member 1B (Abcb1b), Abcc4 and ATP-binding cassette, subfamily A (ABC1), member 8 ( $A b c a 8)$, was also up-regulated by $\alpha$-lipoic acid. $\mathrm{Nr} 1 \mathrm{i} 3$ is a member of the nuclear receptor superfamily and activates many genes involved in drug metabolism $^{(28)}$. $\alpha$-Lipoic acid increased the mRNA expression of this transcription factor.

We also observed that $\alpha$-lipoic acid increased the mRNA expression of miscellaneous proteins involved in the antioxidation system. Metallothionein is a cysteine-rich protein that has marked capacity to bind metal ions. This protein controls metal ion homeostasis and prevents the toxicity of heavy metals. Metallothionein has also been found to perform diverse functions. In particular, this protein has been considered to be a key component of cellular defence against oxidative stress ${ }^{(29)}$. In rats, four types of the metallothionein gene, termed $M t 1 a$, metallothionein 2A $(M t 2 A), M t 3$ and
Mt4, have so far been discovered. $\alpha$-Lipoic acid at a dietary level of $0.5 \%(\mathrm{w} / \mathrm{w})$ caused about a 10 -fold increase in the mRNA expression of $M t 1 a$ and $M t 2 A$. In organisms, two systems are considered critical for general reduction-oxidation (redox) regulation, the thioredoxin and glutaredoxin (Glrx)/ glutathione systems ${ }^{(30)}$. Thioredoxin and thioredoxin reductase and Glrx, glutathione and Gsr represent primary components of the former and latter systems, respectively. In rats, three forms of thioredoxin reductase have been identified (Txnrd1-3). $\alpha$-Lipoic acid caused more than a 2-fold increase in the mRNA expression of Txnrd1 in the present study. Among the proteins involved in the Glrx/glutathione system, $\alpha$-lipoic acid increased the mRNA expression of Gsr, Gclc (a heavy catalytic subunit of glutamate-cysteine ligase that catalyses the first step of glutathione synthesis) and the mitochondrial isoform of Glrx (Glrx2), but unexpectedly decreased the mRNA expression of the cytosolic form of Glrx (Glrx1). Although the magnitude of the increase did not exceed 1.5-fold, $\alpha$-lipoic acid also caused a significant increase in the mRNA expression of a light regulatory subunit of glutamate-cysteine ligase ( Gclm) (1.00 (SEM 0.056) and 1.45 (sem 0.09) in rats fed the $\alpha$-lipoic acid-free diet and the diet containing $0.5 \%(\mathrm{w} / \mathrm{w}) \alpha$-lipoic acid, respectively). The peroxiredoxins function as cysteine-dependent thiol peroxidases that detoxify $\mathrm{H}_{2} \mathrm{O}_{2}$ and lipid peroxides and hence exert cytoprotective and antioxidative effects. Under increased oxidative stress, the cysteine moiety of peroxiredoxins is hyperoxidised to sulfinic acid and hence they lose their peroxidase activity. This inactive form can be reduced back to the active thiol form by sulfiredoxin 1 (Srxn1), an ATPdependent reductase ${ }^{(31)}$. The mRNA expression of this reductase was found to be up-regulated by $\alpha$-lipoic acid in the present study. APEX nuclease 1 (Apex1) is a DNA repair protein that also functions as a redox regulator in mammals ${ }^{(30)}$. $\alpha$-Lipoic acid caused a $2 \cdot 5$-fold increase in the mRNA expression of this protein. Glutathione peroxidase catalyses the reduction of hydroperoxides and $\mathrm{H}_{2} \mathrm{O}_{2}$ by glutathione and thereby protects against oxidative damage. So far, eight different isoforms of glutathione peroxidase have been identified in humans (GPX1-8) and rodents (Gpx1-8). Microarray analysis indicated that $\alpha$-lipoic acid increased the mRNA expression of Gpx2 but not of other Gpx isoforms. 
Table 3. Microarray analysis results for the mRNA of hepatic proteins involved in drug metabolism and prevention of oxidative stress

(Mean values with their standard errors, $n 6$ )

Fold changes (dietary $\alpha$-lipoic acid, wt\%)

\begin{tabular}{|c|c|c|c|c|c|c|}
\hline \multirow[b]{2}{*}{ Accession no. } & \multirow[b]{2}{*}{ Gene symbol } & \multirow[b]{2}{*}{ Gene name } & & \\
\hline & & & Mean & SEM & Mean & SEM \\
\hline \multicolumn{7}{|c|}{ Oxidation, reduction and hydrolysis } \\
\hline M29853 & Cyp4b1 & Cytochrome P450, family 4 , subfamily b, polypeptide 1 & 1.00 & 0.07 & $14 \cdot 9^{* *}$ & 1.7 \\
\hline NM_013215 & Akr7a3 & Aldo-keto reductase family 7 , member A3 (aflatoxin aldehyde reductase) & 1.00 & 0.08 & $8 \cdot 51^{\star *}$ & 0.33 \\
\hline Al454613 & Сур2b12 & Cytochrome P450, family 2, subfamily b, polypeptide 12 & 1.00 & 0.06 & $3 \cdot 80^{\star *}$ & 0.19 \\
\hline BG380693 & Aldh18a1 & Aldehyde dehydrogenase 18 family, member $\mathrm{A} 1$ & 1.00 & 0.08 & $4 \cdot 12^{\star *}$ & 0.46 \\
\hline M23995 & Aldh1a7 & Aldehyde dehydrogenase family 1 , subfamily $A 7$ & 1.00 & 0.31 & $3.52^{\star *}$ & 0.50 \\
\hline NM_022407 & Aldh1a1 & Aldehyde dehydrogenase 1 family, member A1 & 1.00 & 0.19 & $2 \cdot 77^{\star *}$ & 0.20 \\
\hline Al454611 & Fmo5 & Flavin-containing monooxygenase 5 & 1.00 & 0.19 & $2 \cdot 60^{\star \star}$ & 0.36 \\
\hline Al028867 & Akr1d1 & Aldo-keto reductase family 1 , member D1 & 1.00 & 0.13 & $1.99^{\star \star}$ & 0.09 \\
\hline J02679 & Nqo1 & $\mathrm{NAD}(\mathrm{P}) \mathrm{H}$ dehydrogenase, quinone 1 & 1.00 & 0.15 & $1.92^{\star \star}$ & 0.14 \\
\hline NM_133586 & Ces2c & Carboxylesterase 2C & 1.00 & 0.16 & $1.93^{\star *}$ & 0.17 \\
\hline Al072107 & Akr1c1 & Aldo-keto reductase family 1 , member $\mathrm{C} 1$ & 1.00 & 0.22 & $1.76^{\star \star}$ & 0.36 \\
\hline NM_012844 & Ephx1 & Epoxide hydrolase 1 & 1.00 & 0.04 & $1.76^{\star *}$ & 0.09 \\
\hline \multicolumn{7}{|l|}{ Conjugation } \\
\hline AA945082 & Gsta3 & Glutathione $S$-transferase alpha 3 & 1.00 & 0.26 & $51 \cdot 7^{\star *}$ & 3.4 \\
\hline BI300997 & Sult 1c2 & Sulfotransferase family, cytosolic, $1 \mathrm{C}$, member 2 & 1.00 & 0.15 & $13.5^{\star \star}$ & 1.5 \\
\hline NM_133547 & Sult1c2 & Sulfotransferase family, cytosolic, $1 \mathrm{C}$, member 2 & 1.00 & 0.18 & $8 \cdot 86^{* *}$ & 0.8 \\
\hline BM390378 & Gstt3 & Glutathione $S$-transferase, theta 3 & 1.00 & 0.20 & $4 \cdot 83^{\star *}$ & 0.86 \\
\hline X02904 & Gstp1 & Glutathione $S$-transferase pi 1 & 1.00 & 0.05 & $3 \cdot 45^{\star \star}$ & 0.86 \\
\hline M13506 & Ugt2b17 & UDP-glucuronosyltransferase 2 family, polypeptide B17 & 1.00 & 0.17 & $1.94^{\star}$ & 0.46 \\
\hline NM_053293 & Gstt1 & Glutathione $S$-transferase theta 1 & 1.00 & 0.09 & $1.87^{\star *}$ & 0.24 \\
\hline J02612 & $\begin{array}{l}\text { Ugt1a1; Ugt1a6; Ugt1a7; } \\
\text { Ugt1a8; Ugt1a3; Ugt1a10 }\end{array}$ & $\begin{array}{l}\text { UDP-glucuronosyltransferase } 1 \text { family, polypeptide A1; A6; A7; A8; } \\
\text { A2; A3; A10 }\end{array}$ & 1.00 & 0.05 & $1.66^{\star \star}$ & 0.06 \\
\hline BE113459 & Gsto1 & Glutathione $S$-transferase omega 1 & 1.00 & 0.04 & $1.62^{\star \star}$ & 0.07 \\
\hline \multicolumn{7}{|l|}{ Transporters } \\
\hline AF286167 & Abcb1a & ATP-binding cassette, subfamily $B(M D R / T A P)$, member $1 A$ & 1.00 & 0.15 & $6 \cdot 62^{\star *}$ & 0.67 \\
\hline AF257746 & $A b c b 1 a$ & ATP-binding cassette, subfamily B (MDR/TAP), member $1 \mathrm{~A}$ & 1.00 & 0.17 & $3.53^{\star \star}$ & 0.72 \\
\hline AY082609 & $A b c b 1 b ; A b c b 1 a$ & ATP-binding cassette, subfamily $B$ (MDR/TAP), member $1 \mathrm{~B} ; 1 \mathrm{~A}$ & 1.00 & 0.10 & $3.45^{\star *}$ & 0.34 \\
\hline BE100533 & $A b c c 4$ & ATP-binding cassette, subfamily C (CFTR/MRP), member 4 & 1.00 & 0.09 & $3.00^{\star *}$ & 0.23 \\
\hline \multirow{2}{*}{\multicolumn{7}{|c|}{ A IP-Dinaing cassette, subramily A (ABC I), member 8}} \\
\hline & & & & & & \\
\hline NM_022941 & Nr1i3 & Nuclear receptor subfamily 1 , group I, member 3 & 1.00 & 0.18 & $2 \cdot 59^{\star *}$ & 0.13 \\
\hline \multicolumn{7}{|c|}{ Antioxidation system } \\
\hline AF411318 & Mt1a & Metallothionein $1 \mathrm{a}$ & 1.00 & 0.22 & $11 \cdot 6^{\star *}$ & 0.6 \\
\hline BM383531 & Mt2A & Metallothionein $2 \mathrm{~A}$ & 1.00 & 0.13 & $9 \cdot 00^{\star *}$ & 1.56 \\
\hline H31896 & Srxn1 & Sulfiredoxin 1 & 1.00 & 0.05 & $5 \cdot 51^{\star \star}$ & 0.86 \\
\hline AA800587 & Gpx2 & Glutathione peroxidase 2 & 1.00 & 0.18 & $4 \cdot 20^{\star \star}$ & 0.35 \\
\hline AF311054 & Apex 1 & APEX nuclease (multifunctional DNA repair enzyme) 1 & 1.00 & 0.06 & $2.54^{\star *}$ & 0.22 \\
\hline U63923 & Txnrd1 & Thioredoxin reductase 1 & 1.00 & 0.05 & $2 \cdot 43^{\star *}$ & 0.17 \\
\hline NM_031614 & Txnrd1 & Thioredoxin reductase 1 & 1.00 & 0.04 & $2 \cdot 20^{* *}$ & 0.14 \\
\hline NM_053906 & Gsr & Glutathione reductase & 1.00 & 0.07 & $1.94^{\star *}$ & 0.10 \\
\hline AW525635 & G/rx2 & Glutaredoxin 2 & 1.00 & 0.04 & $1.67^{\star *}$ & 0.12 \\
\hline J05181 & Gclc & Glu-Cys ligase, catalytic subunit & 1.00 & 0.04 & $1.65^{\star \star}$ & 0.12 \\
\hline AA848536 & Glrx2 & Glutaredoxin 2 & 1.00 & 0.09 & $1.56^{* *}$ & 0.20 \\
\hline NM_012580 & Hmox1 & Haeme oxygenase (decycling) 1 & 1.00 & 0.10 & $1.52^{\star \star}$ & 0.10 \\
\hline NM_022278 & Glrxy & Glutaredoxin 1 & 1.00 & 0.07 & $0.438^{* *}$ & 0.032 \\
\hline
\end{tabular}

Mean values were significantly different from those of rats fed the $\alpha$-lipoic acid-free diet: ${ }^{*} P<0.05$; ${ }^{* *} P<0.01$ 
Real-time $P C R$ analysis of mRNA expression and determination of enzyme activities

The observations made with DNA microarray analysis revealed that dietary $\alpha$-lipoic acid increased the mRNA expression of proteins involved in drug metabolism and attenuation of oxidative stress. To confirm this observation, we analysed mRNA expression by real-time PCR analysis in rats fed diets containing varying amounts of $\alpha$-lipoic acid. The observations made with real-time PCR analysis essentially confirmed those made with DNA microarray analysis. In fact, $\alpha$-lipoic acid dose dependently increased the mRNA expression of phase I enzymes (Cyp2b12, Cyp4b1, Fmo5, Akr1d1, Akr7a3, Aldh1a1, Nqo1, Ces2c and Ephx1) (Fig. 1), phase II enzymes (Gsta3, Gstp1, Gstt1, Gstt3, Ugt2b1 and Sult1c2) and phase III transporters (Abcb1a and Abcc4) (Fig. 2). We also confirmed that $\alpha$-lipoic acid even at a dietary level of $0.1 \%(\mathrm{w} / \mathrm{w})$ significantly increased the mRNA expression of Nrli3. The magnitudes of the increase observed in rats fed the diet containing $0.5 \%(\mathrm{w} / \mathrm{w}) \alpha$-lipoic acid generally approximated those observed with DNA microarray analysis except for a few genes (Ces2c, Gsta3 and Sult1c2). The extent of changes in the expression of these genes induced by $\alpha$-lipoic acid was considerably lower when the values were obtained using real-time PCR than when obtained using DNA microarray analysis.

As $\alpha$-lipoic acid increased the mRNA expression of some Gst isoenzymes, we analysed the activity of Gst using four different substrates (1-chloro-2,4-dinitrobenzene, 1,2-dichloro-4-nitrobenzene, p-nitrobenzyl chloride and ethacrynic acid). The enzyme activity measured using 1-chloro-2,4-dinitrobenzene as a substrate was significantly higher in rats fed diets containing various amounts of $\alpha$-lipoic acid than in those fed the diet free of this compound (Fig. 3). The activity of the enzyme measured using this substrate was about 1.5 times higher in rats fed the diet containing $0.5 \%(\mathrm{w} / \mathrm{w}) \alpha$-lipoic acid than in those fed the diet free of this compound. Significant but less prominent increases in enzyme activity were also observed when 1,2-dichloro-4-nitrobenzene was used as a substrate in rats fed diets containing 0.25 and $0.5 \%(\mathrm{w} / \mathrm{w}) \alpha$-lipoic acid than in those fed the $\alpha$-lipoic acid-free diet. However, significant increases in enzyme activity in rats fed diets containing various amounts of $\alpha$-lipoic were not observed when using p-nitrobenzyl chloride and ethacrynic acid as substrates (data not shown).

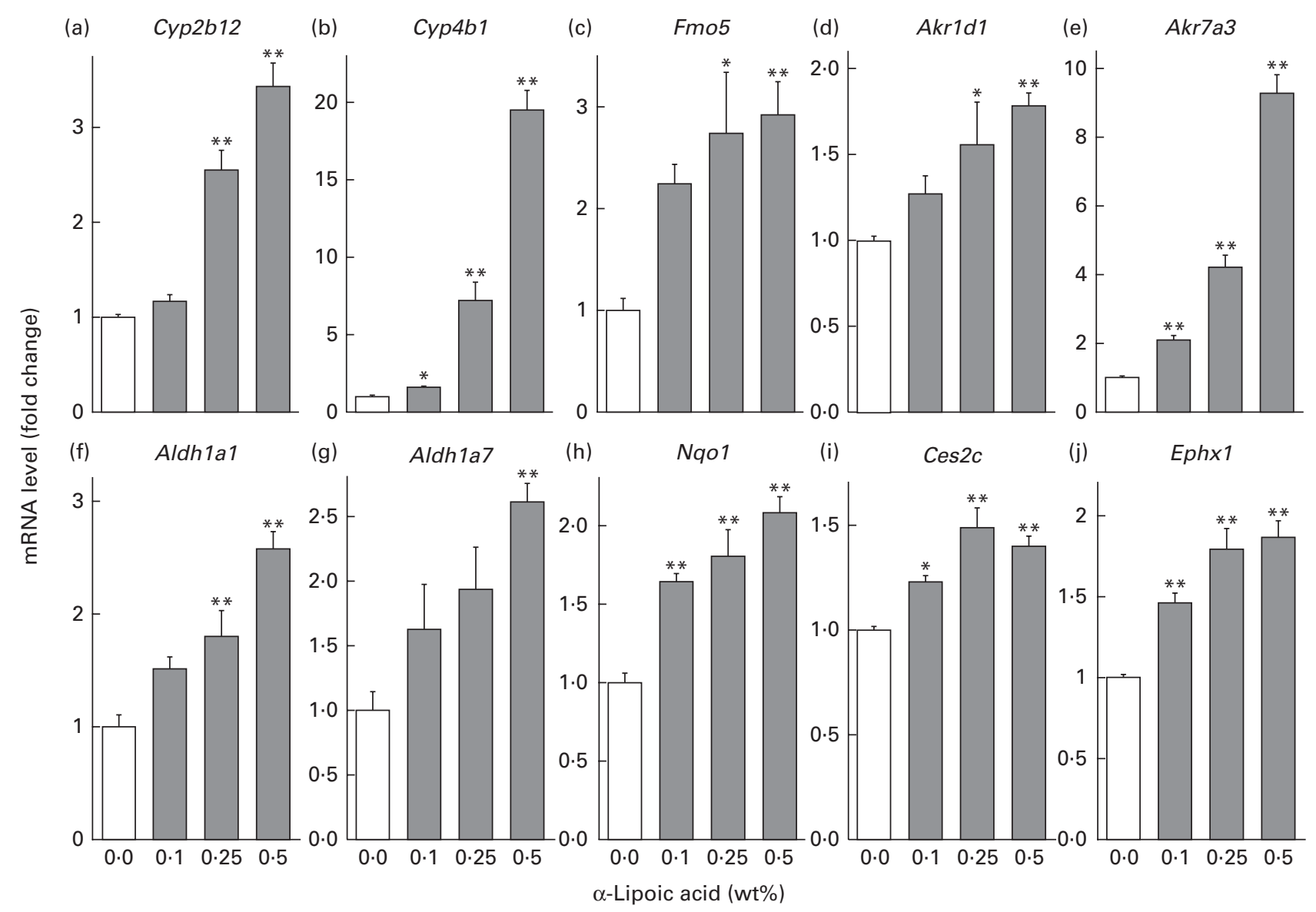

Fig. 1. Levels of the mRNA of enzymes involved in phase I reactions in drug metabolism in the liver of rats fed diets containing various amounts of $\alpha$-lipoic acid. The levels of mRNA were quantified using real-time PCR analysis. (a) Cyp2b12, (b) Cyp4b1, (c) Fmo5, (d) Akr1d1, (e) Akr7a3, (f) Aldh1a1, (g) Aldh1a7, (h) Nqo1, (i) Ces2c, (j) Ephx1. Values are means, with their standard errors represented by vertical bars $(n 7)$. Mean values were significantly different from those of rats fed the $\alpha$-lipoic acid-free diet: ${ }^{*} P<0.05 ;{ }^{* *} P<0.01$. The names of genes represented by gene symbols are given in Table 3 . 


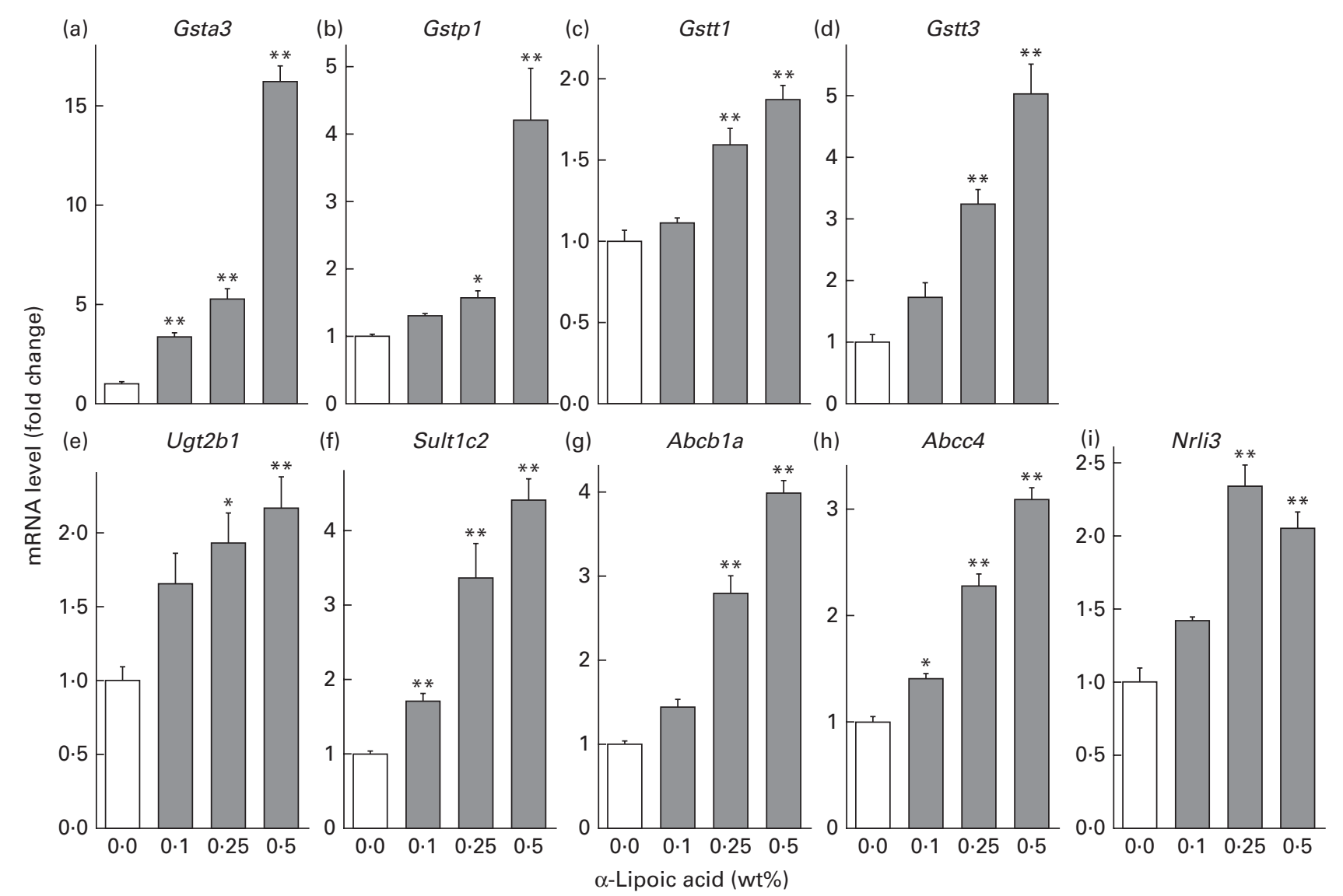

Fig. 2. Levels of the mRNA of enzymes involved in phase II conjugation reactions and phase III transportation in drug metabolism as well as a transcription factor regulating the gene expression of drug-metabolising enzymes in the liver of rats fed diets containing various amounts of $\alpha$-lipoic acid. The levels of mRNA were quantified using real-time PCR analysis. (a) Gsta3, (b) Gstp1, (c) Gstt1, (d) Gstt3, (e) Ugt2b1, (f) Sult1c2, (g) Abcb1a, (h) Abcc4 and (i) Nr1i3. Values are means, with their standard errors represented by vertical bars $(n 7)$. Mean values were significantly different from those of rats fed the $\alpha$-lipoic acid-free diet: * $P<0.05$; ${ }^{\star *} P<0.01$. The names of genes represented by gene symbols are given in Table 3 .

In Fig. 4(a), the effect of dietary $\alpha$-lipoic acid on the mRNA levels of proteins involved in the thiol redox regulation system and Mt1a analysed by real-time PCR analysis among rats fed diets containing varying amounts of $\alpha$-lipoic acid is shown. The results obtained using DNA microarray analysis were generally confirmed using real-time PCR analysis; that is, dietary $\alpha$-lipoic acid dose dependently increased the mRNA levels of Gsr, Gpx2, Gclc, Gclm, Glrx2, Txnrd1, Srnx1 and Apex1. The decrease in the mRNA expression of Glrx 1 caused by the diet containing $0.5 \%(\mathrm{w} / \mathrm{w}) \alpha$-lipoic acid observed using DNA microarray analysis was also observed using real-time PCR analysis. However, the decrease was considerably attenuated when the parameter was analysed using real-time PCR analysis. A significant decrease in this parameter was not confirmed in rats fed diets containing 0.1 and $0.25 \%(\mathrm{w} / \mathrm{w})$ $\alpha$-lipoic acid. As $\alpha$-lipoic acid increased the mRNA expression of subunits of a rate-limiting enzyme in glutathione biosynthesis, we measured hepatic glutathione concentration (Fig. 4(b)). Dietary $\alpha$-lipoic acid dose dependently increased this parameter, and values observed in rats fed diets containing 0.25 and $0.5 \%(\mathrm{w} / \mathrm{w}) \quad \alpha$-lipoic acid were significantly higher than those in rats fed the diet free of $\alpha$-lipoic acid. We also measured the activity of Gsr (Fig. 4(c)). Dietary $\alpha$-lipoic acid dose dependently increased the activity of this enzyme. Consistent with the observation that $\alpha$-lipoic acid increased the mRNA expression of proteins involved in the redox system, $\alpha$-lipoic acid strongly and dose dependently reduced the concentrations of malondialdehyde, a marker of lipid peroxidation, in both the serum and liver (Fig. 4(d)).

\section{Discussion}

Previous studies have indicated that $\alpha$-lipoic acid increases the mRNA expression or the activity or protein levels of enzymes involved in drug metabolism, including $\mathrm{NAD}(\mathrm{P}) \mathrm{H}$ :quinone oxidoreductase $^{(16-18)}$, Gst- $\alpha 2$ and microsomal epoxide hydrolase ${ }^{(18)}$, in various types of cultured cells. However, an animal study examining the physiological activity of $\alpha$-lipoic acid affecting drug-metabolising enzymes has been lacking.

The present study using DNA microarray analysis unequivocally demonstrated that dietary $\alpha$-lipoic acid up-regulates the gene expression of various proteins involved in drug metabolism. Drug metabolism involves many enzymes that catalyse numerous types of chemical reactions, and each reaction is often catalysed by many isoenzymes differing in substrate specificity. Therefore, the DNA microarray technique is quite useful for identifying isoenzymes involved in drug metabolism 
(a)

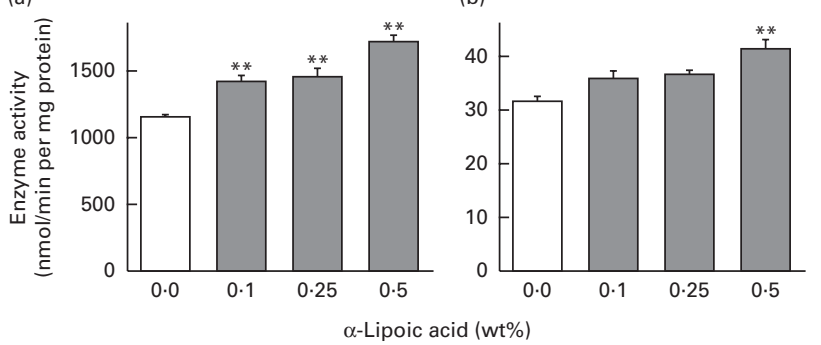

Fig. 3. Activity of glutathione transferase in the liver of rats fed diets containing various amounts of $\alpha$-lipoic acid. Enzyme activity was measured using (a) 1-chloro-2,4-dinitrobenzene and (b) 1,2-dichloro-4-nitrobenzene as substrates. Values are means, with their standard errors represented by vertical bars $(n 7)$. Mean values were significantly different from those of rats fed the $\alpha$-lipoic acid-free diet: ${ }^{\star} P<0.05 ;{ }^{\star \star} P<0.01$.

specifically affected by various physiological and dietary factors.

The Cyp proteins are a superfamily of enzymes highly expressed in the liver and involved in the metabolism of xenobiotic compounds, as well as the synthesis and catabolism of endogenous compounds. Among the various $C y p$, DNA microarray and real-time PCR analyses revealed that $\alpha$-lipoic acid dose dependently increased the mRNA expression of Cyp4b1 and Cyp2b12. Cyp4b1 is involved in the $\omega$-oxidation of lauric acid and mutagenic activation of some chemical compounds ${ }^{(32,33)}$. Some xenobiotic compounds, such as terephthalic acid, have been shown to increase the mRNA expression of Cyp4b1 in the liver ${ }^{(34)}$, and caffeic acid has been shown to increase the mRNA expression in the colon $^{(35)}$. The role of Cyp2b12 in hepatic drug metabolism is not clear.

Fmo are another superfamily of enzymes involved in drug metabolism $^{(36)}$ and are expressed at high levels in the liver. Many different enzyme genes have been identified in mammals. Studies have indicated that Fmo1, Fmo3 and Fmo5 are the major Fmo in mouse liver and Fmo5 predominates over the other two isoforms ${ }^{(37)}$. DNA microarray analysis revealed that the mRNA expression of Fmo5 but not of other Fmo was up-regulated by dietary $\alpha$-lipoic acid. Some studies ${ }^{(37,38)}$ have shown that Fmo5, similar to other Fmo, can oxidise various endogenous and xenobiotic substrates.

Many aldehydes generated during normal physiological processes are cytotoxic and carcinogenic. Aldh detoxify various aldehydes. Aldh is a superfamily consisting of many genes. In the present study, $\alpha$-lipoic acid increased the mRNA expression of Aldb1a1, Aldb1a7 and Aldb18a1. Studies have indicated that Aldh1a1 is involved in the detoxification of various xenobiotic aldehydes ${ }^{(39)}$. As Aldh1a1 and Aldh1a7 appear to be coordinately regulated ${ }^{(40,41)}$, it is plausible that not only Aldh1a1 but also Aldh1a7 plays a crucial role in drug metabolism. The role of Aldh18a1 in drug metabolism is not clear at present.

The role of Nqo1 and Ephx1 in drug metabolism has been well documented ${ }^{(42,43)}$. In the present study, we observed that $\alpha$-lipoic acid increased the mRNA expression of these enzymes. This is agreement with the results of previous studies in cultured cells ${ }^{(16-18)}$.
It has been suggested that various Akr isoenzymes are involved in the detoxification of lipid aldehydes and various xenobiotic compounds ${ }^{(44)}$. DNA microarray and real-time PCR analyses revealed that $\alpha$-lipoic acid dose dependently increased the mRNA expression of $A k r 7 a 3, A k r 1 d 1$ and Akr1c1. Akr7a3, alternatively known as aflatoxin aldehyde reductase, was discovered ${ }^{(45)}$ as an enzyme to reduce aflatoxin B1-dihydrodiol to the dialcohol metabolite in rats. Studies ${ }^{(46,47)}$ have demonstrated that this enzyme also reduces various aldehyde and keto substrates. In addition, studies $^{(46-48)}$ have shown that many compounds having chemopreventive properties increase the expression of this enzyme. Studies have indicated that Akr1c1 plays a crucial role in the metabolism of xenobiotic compounds and in chemoprevention ${ }^{(49)}$. Akr1d1 may play a crucial role in bile acid synthesis $^{(50)}$ rather than in drug metabolism. Data suggest that several Akr isoforms convert polycyclic aromatic hydrocarbons into carcinogenic compounds, referred to as remote quinones $^{(51)}$. This does not comply with the consideration that Akr are involved in chemoprevention.

Carboxylesterases comprise a superfamily of microsomal enzymes that catalyse the hydrolysis of a variety of esterand amide-containing chemicals to their respective free acids. They are involved in the detoxification or metabolic activation of xenobiotic compounds ${ }^{(52)}$. Dietary $\alpha$-lipoic acid increased the mRNA expression of Ces $2 c$ but not of other isoenzymes. Ces2 isoforms can hydrolyse various xenobiotic compounds ${ }^{(52)}$. Therefore, the increase in the mRNA expression of a member of the Ces 2 family may stimulate the metabolism of xenobiotic compounds.

More than twenty Gst isoenzymes have so far been identified in rats. In spite of the fact that the DNA microarray contained nineteen probes for various Gst, we observed that the diet containing $0.5 \%(\mathrm{w} / \mathrm{w}) \quad \alpha$-lipoic acid significantly increased the mRNA expression of Gsta3, Gstt1 and Gstt3, Gstp1 and Gsto1 but not of other Gst more than 1.5-fold. Therefore, the effect of $\alpha$-lipoic acid on the mRNA expression of Gst was again isoenzyme specific. It has been reported that several synthetic or natural compounds with anti-carcinogenic activities increase the mRNA or protein expression of Gsta3 and Gstp1 in rat liver ${ }^{(47,53)}$. So, it is possible that these isoforms play a role in the detoxification of xenobiotic compounds and cancer prevention. Also, some epidemiological surveys have indicated that GSTT1 deletion in humans increases the risk of cancer ${ }^{(54)}$. Gstt3 has so far been identified in mice and rats and is highly expressed in the liver ${ }^{(55)}$. However, the physiological significance of this Gst isoenzyme in detoxification and cancer prevention is not known. Gsto1 is expressed abundantly in the liver, macrophages, and glial and endocrine cells ${ }^{(56)}$, but information regarding the role of this isoform in drug metabolism is scarce. A case-control study failed to find a clear-cut relationship between GSTO1 polymorphisms and cancer risk ${ }^{(57)}$. We observed that dietary $\alpha$-lipoic acid increased cytosolic Gst activity when using 1-chloro-2,4-dinitrobenzene and 1,2-dichloro-4-nitrobenzene as substrates. However, the extent of the increases was much lower than that observed for the mRNA levels of Gsta3, Gstt1 and Gstt3, Gstp1 and Gsto1. This is not surprising 


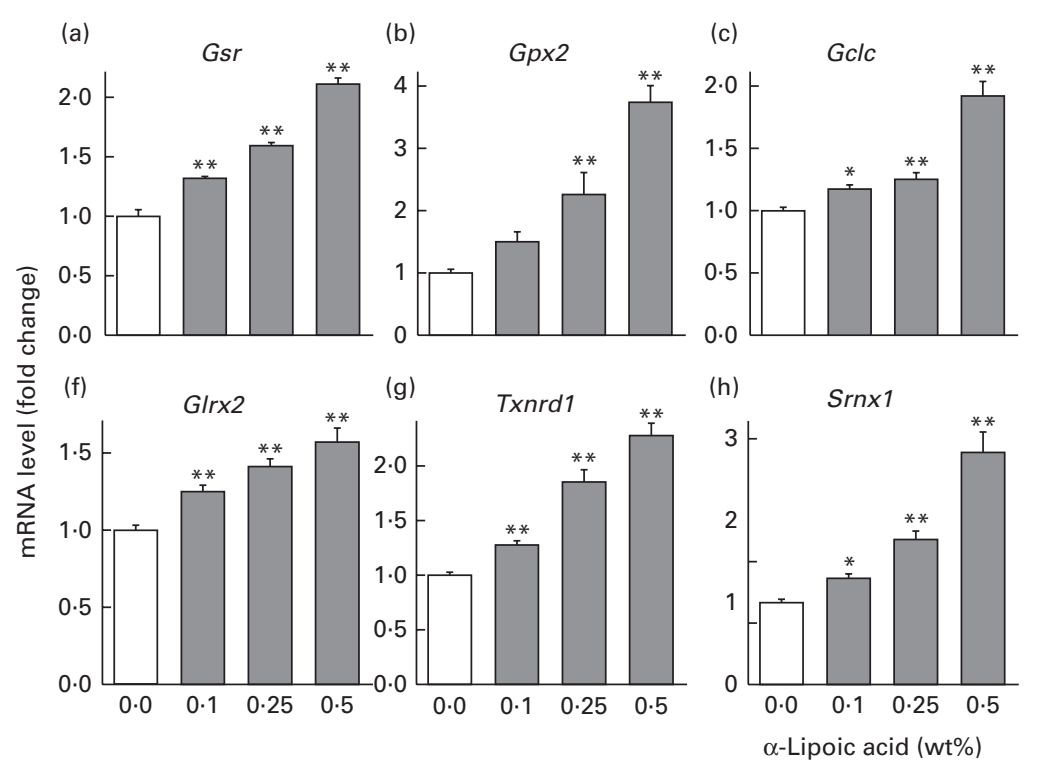

(k)

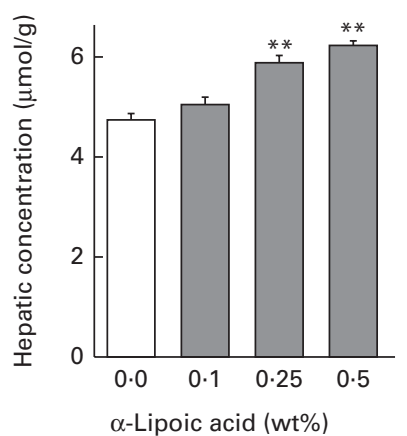

(I)

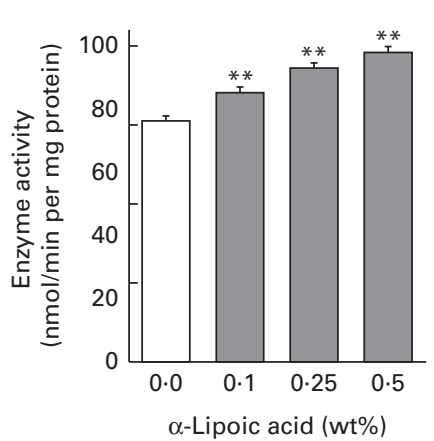

(m) (d)

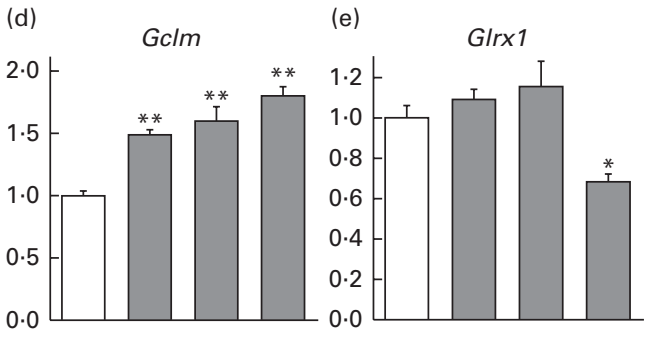

(i) Apex1

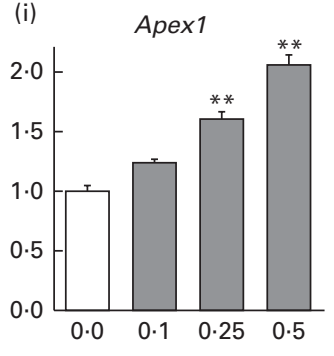

(j) Mt1a

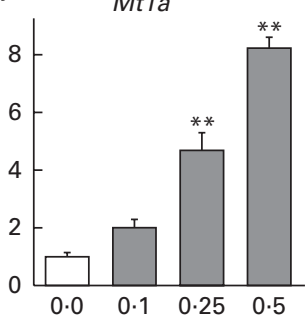

Fig. 4. Levels of the mRNA of proteins involved in the antioxidation system ((a) Gsr, (b) Gpx2, (c) Gclc, (d) Gclm, (e) Glrx1, (f) Glrx2, (g) Txnrd1, (h) Srnx1, (i) Apex1, (j) Mt1a), (k) concentration of glutathione, (I) activity of glutathione reductase in the liver as well as concentrations of malondialdehyde in the ( $\mathrm{m}$ ) serum and $(n)$ liver of rats fed diets containing various amounts of $\alpha$-lipoic acid. The levels of mRNA were quantified using real-time PCR analysis. Values are means, with their standard errors represented by vertical bars $(n 7)$. Mean values were significantly different from those of rats fed the $\alpha$-lipoic acid-free diet: * $P<0.05$; ${ }^{\star \star} P<0.01$. The names of genes represented by gene symbols are given in Table 3 .

because the effect of $\alpha$-lipoic acid on Gst was isoenzyme specific and it did not affect the mRNA levels of many other $G s t$. $\alpha$-Lipoic acid failed to affect enzyme activity when using p-nitrobenzyl chloride and ethacrynic acid as substrates. The substrate specificity of each Gst isoenzyme differs considerably $^{(56)}$. Therefore, it is reasonable that $\alpha$-lipoic acid did not increase the amount of Gst molecules, which is specific to p-nitrobenzyl chloride and ethacrynic acid.

Cytosolic Sult are phase II drug-metabolising enzymes. In mammals, four to five gene families of Sult have been identified $^{(58)}$. Each family comprises more than one member, and the DNA microarray used in the present study contained seven probes for various Sult1 family members, five for Sult2 family members, and one each for Sult 4 and Sult5 members. Among the various Sult, $\alpha$-lipoic acid increased the mRNA expression of Sult1c2, but not of the other isoforms. It has been reported that phenolic compounds including carcinogens can serve as substrates for Sult belonging to the $1 \mathrm{c}$ family ${ }^{(58)}$.

Among the various Ugt isoenzymes, $\alpha$-lipoic acid significantly increased the mRNA expression of UDP
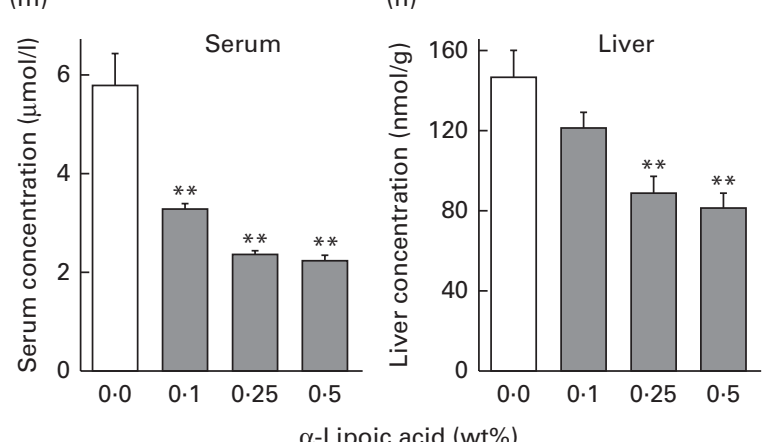

glucuronosyltransferase 2 family, polypeptide B17 (Ugt2b17) and isoenzyme(s) belonging to the Ugt1a family. Ugt belonging to $1 \mathrm{a}$ and $2 \mathrm{~b}$ families are abundantly expressed in the liver and catalyse the glucuronidation of various endogenous and xenobiotic compounds ${ }^{(59)}$.

The Abc transporters transport a wide variety of exogenous and endogenous substances across membranes. There are seven subfamilies, termed Abca, Abcb, Abcc, Abcd, Abce, Abcf and Abcg. Many Abc transporters are involved in the export of xenobiotic compounds and hence in drug resistance. In the present study, $\alpha$-lipoic acid increased the mRNA expression of three Abc transporters (one each from Abca, $\mathrm{Abcb}$ and Abcc subfamilies). As these Abc subfamilies play crucial roles in the export of xenobiotics out of the cell ${ }^{(60)}$, $\alpha$-lipoic acid may stimulate drug metabolism through the up-regulation of not only phase I and II enzymes but also phase III transporters.

$\alpha$-Lipoic acid increased the mRNA expression of Nr1i3, alternatively known as constitutive androstane/ activated receptor (Car). This transcription factor activates various genes involved in drug metabolism ${ }^{(28)}$. 
Therefore, up-regulation of the mRNA expression of this transcription factor may account for the $\alpha$-lipoic acid-dependent increase in the mRNA levels of various proteins involved in drug metabolism.

In the present study, we demonstrated that $\alpha$-lipoic acid increases the gene expression of proteins involved in the antioxidation system in addition to that of those involved in drug metabolism. The observations that $\alpha$-lipoic acid increased hepatic glutathione concentration and mRNA levels of two subunits of $\gamma$-glutamylcysteine ligase ( $\mathrm{Gclc}$ and $\mathrm{Gclm}$ ) were in agreement with those made by Suh et al. ${ }^{(61)}$. Xu et al. ${ }^{(8)}$ have also recently reported that $\alpha$-lipoic acid increases hepatic glutathione concentration and activities of enzymes involved in the antioxidation system. Moreover, in the present study using DNA microarray analysis, we demonstrated that $\alpha$-lipoic acid increases the mRNA expression of various other proteins presumed to be involved in the thiol redox system, including Srxn1, Gpx2, Apex1, Txnrd1, Gsr and Glrx2 (cytosolic form of Glrx), but decreases that of the mitochondrial form of Glrx (Glrx1). However, real-time PCR analysis indicated that $\alpha$-lipoic acid is rather weak in terms of affecting the mRNA expression of Glrx 1 . In addition to the proteins involved in the thiol redox system, $\alpha$-lipoic acid significantly increased the mRNA expression of metallothioneins ( $M t 1 a$ and $M t 2 A$ ). Studies have indicated that metallothionein plays a crucial role in the prevention of oxidative stress in animals ${ }^{(29)}$. Haeme oxygenase is involved in the conversion of haeme into strong antioxidants (biliverdin and biliverdin $)^{(62)}$. Therefore, haeme oxygenase is considered to play a decisive role in the attenuation of the oxidative process. So far, two forms of haeme oxygenase (Hmox1 and Hmox2) have been identified in both humans and rodents. Hmox1 but not Hmox2 is considered to play a crucial role in protection against oxidative stress ${ }^{(62)}$.

Some previous studies ${ }^{(61,63,64)}$ have indicated that $\alpha$-lipoic acid increases the expression of genes involved in the antioxidation system. The present study extended this evidence and newly identified many genes involved in the antioxidation system that are affected by $\alpha$-lipoic acid. Therefore, it is plausible that this at least partly accounts for the potent antioxidation activity of dietary $\alpha$-lipoic acid, as confirmed in the present study using malondialdehyde as a marker of lipid peroxidation.

A transcription factor called nuclear factor, erythroid derived 2, like 2 (Nfe212) or NFE2-related factor 2 ( Nrf2) regulates the gene expression of many enzymes involved in the antioxidation system and drug metabolism ${ }^{(61,65)}$. There is a possibility that this transcription factor is involved in $\alpha$-lipoic acid-dependent changes in the mRNA expression of proteins involved in drug metabolism and the antioxidation system. In fact, the mRNA expression of many genes targeted by this transcription factor, such as Nqo1, Hmox1, subunits of glutamate-cysteine ligase (Gclm and Gclc), Ephx1, Srxn1 and Abcc4, was upregulated by dietary $\alpha$-lipoic acid. Moreover, recent studies have indicated that Nrf2 is also involved in the regulation of hepatic lipid biosynthesis ${ }^{(6)}$. Therefore, alterations in the Nrf2 signalling pathway may account for not only the $\alpha$-lipoic acid-dependent changes in the mRNA expression of proteins involved in drug metabolism and the antioxidation system observed in the present study, but also the reduction in lipid biosynthesis reported previously ${ }^{(12-14)}$.

Finlay et $a l .{ }^{(67)}$ have recently reported the results of DNA microarray analysis on the hepatic gene expression of young and old rats fed $\alpha$-lipoic acid. Consistent with our previous studies $^{(12-14)}$ and the present study, they found that $\alpha$-lipoic acid strongly reduced the mRNA levels of proteins involved in lipogenesis. They also suggested that $\alpha$-lipoic acid altered the expression of genes governing circadian rhythm. However, they did not make any comment regarding the effect of $\alpha$-lipoic acid on proteins involved in drug metabolism and in the antioxidation system.

Previous animal experiments ${ }^{(8-11,63)}$ using rats or mice have employed dietary levels of $\alpha$-lipoic acid of $0.05-1 \%(w / w)$, which are similar to the levels employed in the present study. A nutritional survey conducted in the UK in 2008-9 ${ }^{(68)}$ has indicated the median food intake of adult humans to be 435 and $338 \mathrm{~g} / \mathrm{d}$ for men and women, respectively. A nutritional survey conducted in Japan in 2011 (http://www.mhlw. go.jp/stf/houdou/2r9852000002q1st-att/2r9852000002q1wo.pdf) has also indicated the average food intake of adult humans to be 447 and $374 \mathrm{~g} / \mathrm{d}$ for men and women, respectively. Therefore, the intake of diets containing $0 \cdot 1,0.25$ and $0.5 \%(\mathrm{w} / \mathrm{w})$ $\alpha$-lipoic acid used in the present animal study corresponds to the daily consumption of approximately 340-450, $850-1100$ and $1700-2200 \mathrm{mg} /$ person of this compound, respectively, when extrapolated to humans. These values are comparable to those employed in previous human studies $(200-2400 \mathrm{mg} / \mathrm{d} \text { per person })^{(2)}$. With regard to the safe dose level of $\alpha$-lipoic acid, the acute $\mathrm{LD}_{50}$ (lethal dose $50 \%$ ) appeared to be very high in rats $(>2000 \mathrm{mg} / \mathrm{kg}$ body weight), although lower values have been reported in some other species (dogs, mice and cats) and the NOAEL (no observed adverse effect level) has been estimated to be $61.9 \mathrm{mg} \alpha$-lipoic acid/kg body weight per $\mathrm{d}$ for rats $^{(2)}$. On the basis of the body weight and food intake of rats observed in the present study, approximate dose levels of $\alpha$-lipoic acid were estimated to be 16,40 and $80 \mathrm{mg} / \mathrm{kg}$ body weight per $\mathrm{d}$ for animals fed diets containing this compound at the levels of $0.1, \quad 0.25$ and $0.5 \%(\mathrm{w} / \mathrm{w})$, respectively. Therefore, these values did not markedly exceed the NOAEL of $\alpha$-lipoic acid, although dietary levels of 0.25 and $0.5 \%(\mathrm{w} / \mathrm{w}$ ) significantly reduced the body weight of animals. The diet containing $0.25 \%(\mathrm{w} / \mathrm{w}) \alpha$-lipoic acid reduced the growth of rats without significantly affecting food intake in the present study. In this context, it has been reported that $\alpha$-lipoic acid increases energy expenditure ${ }^{(69,70)}$ and reduces intestinal sugar absorption $^{(71)}$ in rats.

It has been reported that orally administered $\alpha$-lipoic acid in rats is well absorbed from the intestine ${ }^{(2,72)}$. Pharmacokinetic analyses of the metabolic fate of orally and intravenously administered radiolabelled $\alpha$-lipoic acid have indicated that $66 \%$ of orally administered $\alpha$-lipoic acid is absorbed from the intestine. An alternative evaluation based on the measurements of urinary excretion of ${ }^{14} \mathrm{C}$ gave a higher value of absorption $(93 \%)^{(72)}$.

In conclusion, DNA microarray and real-time PCR analyses revealed that dietary $\alpha$-lipoic acid strongly increases the 
mRNA expression of various proteins involved in drug metabolism and the antioxidation system. Therefore, it is expected that $\alpha$-lipoic acid would be effective at ameliorating pathological conditions induced by physiological factors and xenobiotic toxic compounds. In this context, it has been well demonstrated that compounds having the propensity to increase the activity and gene expression of enzymes involved in drug metabolism exhibit chemopreventive effects. In fact, some studies have indicated that $\alpha$-lipoic acid is effective against tumour development ${ }^{(73)}$. Evaluation of the physiological effect of $\alpha$-lipoic acid in pathological conditions would clarify the physiological significance of the up-regulation of the gene expression of proteins involved in drug metabolism and antioxidation by $\alpha$-lipoic acid. This needs to be clarified in future studies.

\section{Acknowledgements}

The present study was supported by a grant-in-aid for scientific research (Scientific Research C, no. 22580143) from the Japan Society for the Promotion of Science and a grant from the Ministry of Agriculture, Forestry, and Fisheries research project 'Development of evaluation and management methods for supply of safe, reliable and functional food and farm produce'.

The author's contributions are as follows: T. I. designed and carried out the animal experiment, analysed the data and prepared the manuscript.

The author declares no conflicts of interest.

\section{References}

1. Shay KP, Moreau RF, Smith EJ, et al. (2009) Alpha-lipoic acid as a dietary supplement: molecular mechanisms and therapeutic potential. Biochim Biophys Acta 1790, 1149-1160.

2. Wollin SD \& Jones PJ (2003) $\alpha$-Lipoic acid and cardiovascular disease. J Nutr 133, 3327-3330.

3. Durrani AI, Schwartz H, Nagl M, et al. (2010) Determination of free $\alpha$-lipoic acid in foodstuffs by HPLC coupled with CEAD and ESI-MS. Food Chem 120, 1143-1148.

4. Amudha G, Josephine A \& Varalakshmi P (2006) Role of lipoic acid in reducing the oxidative stress induced by cyclosporin A. Clin Chim Acta 372, 134-139.

5. Thirunavukkarasu V \& Anuradha CV (2004) Influence of $\alpha$-lipoic acid on lipid peroxidation and antioxidant defence system in blood of insulin-resistant rats. Diabetes Obes Metab 6, 200-207.

6. Bilska A \& Włodek L (2005) Lipoic acid - the drug of the future? Pharmacol Rep 57, 570-577.

7. Henriksen EJ, Diamond-Stanic MK \& Marchionne EM (2011) Oxidative stress and the etiology of insulin resistance and type 2 diabetes. Free Radic Biol Med 51, 993-999.

8. Xu J, Gao H, Song L, et al. (2013) Flaxseed oil and alphalipoic acid combination ameliorates hepatic oxidative stress and lipid accumulation in comparison to lard. Lipids Health Dis 12, 58.

9. Yi X \& Maeda N (2006) $\alpha$-Lipoic acid prevents the increase in atherosclerosis induced by diabetes in apolipoprotein E-deficient mice fed high-fat/low-cholesterol diet. Diabetes 55, 2238-2244.
10. Song KH, Lee WJ, Koh JM, et al. (2005) $\alpha$-Lipoic acid prevents diabetes mellitus in diabetes-prone obese rats. Biochem Biophys Res Commun 326, 197-202.

11. Ford I, Cotter MA, Cameron NE, et al. (2001) The effects of treatment with $\alpha$-lipoic acid or evening primrose oil on vascular hemostatic and lipid risk factors, blood flow, and peripheral nerve conduction in the streptozotocin-diabetic rat. Metabolism 50, 868-875.

12. Huong DT \& Ide T (2008) Dietary lipoic acid-dependent changes in the activity and mRNA levels of hepatic lipogenic enzymes in rats. BrJ Nutr 100, 79-87.

13. Ide T, Azechi A, Suzuki N, et al. (2013) Effects of dietary $\alpha$-lipoic acid enantiomers on hepatic fatty acid metabolism in rats. J Funct Foods 5, 71-79.

14. Ide T, Azechi A, Kitade S, et al. (2013) Combined effect of sesamin and $\alpha$-lipoic acid on hepatic fatty acid metabolism in rats. Eur J Nutr 52, 1015-1027.

15. Orrenius S \& Ericsson JL (1965) Phenobarbital-induced synthesis of the microsomal drug-metabolizing enzyme system and its relationship to the proliferation of endoplasmic membranes. A morphological and biochemical study. J Cell Biol 25, 627-639.

16. Jia Z, Hallur S, Zhu H, et al. (2008) Potent upregulation of glutathione and $\mathrm{NAD}(\mathrm{P}) \mathrm{H}$ :quinone oxidoreductase 1 by alpha-lipoic acid in human neuroblastoma SH-SY5Y cells: protection against neurotoxicant-elicited cytotoxicity. Neurochem Res 33, 790-800.

17. Elangovan S \& Hsieh TC (2008) Control of cellular redox status and upregulation of quinone reductase NQO1 via $\mathrm{Nrf} 2$ activation by $\alpha$-lipoic acid in human leukemia HL-60 cells. Int J Oncol 33, 833-838.

18. Ki SH \& Kim SG (2008) Phase II enzyme induction by alphalipoic acid through phosphatidylinositol 3-kinase-dependent C/EBPs activation. Xenobiotica 38, 587-604.

19. Odbayar TO, Kimura T, Tsushida T, et al. (2009) Isoenzymespecific up-regulation of glutathione transferase and aldoketo reductase mRNA expression by dietary quercetin in rat liver. Mol Cell Biochem 325, 121-130.

20. Reeves PG, Nielsen FH \& Fahey GC Jr (1993) AIN-93 purified diets for laboratory rodents: final report of the American Institute of Nutrition ad hoc writing committee on the reformulation of the AIN-76A rodent diet. J Nutr 123, 1939-1951.

21. Niebch G, Büchele B, Blome J, et al. (1997) Enantioselective high-performance liquid chromatography assay of $(+) \mathrm{R}-$ and $(-)$ S- $\alpha$-lipoic acid in human plasma. Chirality 9, 32-36.

22. Chomczynski P \& Sacchi N (1987) Single-step method of RNA isolation by acid guanidinium thiocyanate-phenolchloroform extraction. Anal Biochem 162, 156-159.

23. Ide $\mathrm{T}$ (2005) Interaction of fish oil and conjugated linoleic acid in affecting hepatic activity of lipogenic enzymes and gene expression in liver and adipose tissue. Diabetes $\mathbf{5 4}$, 412-423.

24. Habig WH \& Jakoby WB (1981) Assays for differentiation of glutathione S-transferases. Methods Enzymol 77, 398-405.

25. Carlberg I \& Mannervik B (1985) Glutathione reductase. Methods Enzymol 113, 484-490.

26. Anderson ME (1985) Determination of glutathione and glutathione disulfide in biological samples. Methods Enzymol 113, 548-555.

27. Khoschsorur GA, Winklhofer-Roob BM, Rabl H, et al. (2000) Evaluation of a sensitive HPLC method for the determination of malondialdehyde, and application of the method to different biological materials. Chromatographia 52, 181-184.

28. Tolson AH \& Wang H (2010) Regulation of drug-metabolizing enzymes by xenobiotic receptors: PXR and CAR. $A d v$ Drug Deliv Rev 62, 1238-1249. 
29. Swindell WR (2011) Metallothionein and the biology of aging. Ageing Res Rev 10, 132-145.

30. Luo M, He H, Kelley MR, et al. (2010) Redox regulation of DNA repair: implications for human health and cancer therapeutic development. Antioxid Redox Signal 12, 1247-1269.

31. Soriano FX, Baxter P, Murray LM, et al. (2009) Transcriptional regulation of the AP-1 and Nrf2 target gene sulfiredoxin. Mol Cells 27, 279-282.

32. Imaoka S, Yoneda Y, Matsuda T, et al. (1997) Mutagenic activation of urinary bladder carcinogens by CYP4B1 and the presence of CYP4B1 in bladder mucosa. Biochem Pharmacol 54, 677-683.

33. Imaoka S, Hayashi $\mathrm{K}$, Hiroi $\mathrm{T}$, et al. (2001) A transgenic mouse expressing human CYP4B1 in the liver. Biochem Biophys Res Commun 284, 757-762.

34. Dai GD, Cui LB, Song L, et al. (2006) Metabolism of terephthalic acid and its effects on CYP4B1 induction. Biomed Environ Sci 19, 8-14.

35. Ye Z, Liu Z, Henderson A, et al. (2009) Increased CYP4B1 mRNA is associated with the inhibition of dextran sulfate sodium-induced colitis by caffeic acid in mice. Exp Biol Med 234, 605-616.

36. Krueger SK \& Williams DE (2005) Mammalian flavin-containing monooxygenases: structure/function, genetic polymorphisms and role in drug metabolism. Pharmacol Ther 106, 357-387.

37. Zhang J, Cerny MA, Lawson M, et al. (2007) Functional activity of the mouse flavin-containing monooxygenase forms 1, 3, and 5. J Biochem Mol Toxicol 21, 206-215.

38. Cherrington NJ, Falls JG, Rose RL, et al. (1998) Molecular cloning, sequence, and expression of mouse flavin-containing monooxygenases 1 and 5 (FMO1 and FMO5).J Biochem Mol Toxicol 12, 205-212.

39. Marchitti SA, Brocker C, Stagos D, et al. (2008) Non-P450 aldehyde oxidizing enzymes: the aldehyde dehydrogenase superfamily. Expert Opin Drug Metab Toxicol 4, 697-720.

40. Alnouti Y \& Klaassen CD (2008) Tissue distribution, ontogeny, and regulation of aldehyde dehydrogenase (Aldh) enzymes mRNA by prototypical microsomal enzyme inducers in mice. Toxicol Sci 101, 51-64.

41. Tsuruoka N, Kidokoro A, Matsumoto I, et al. (2005) Modulating effect of sesamin, a functional lignan in sesame seeds, on the transcription levels of lipid- and alcohol-metabolizing enzymes in rat liver: a DNA microarray study. Biosci Biotechnol Biochem 69, 179-188.

42. Dinkova-Kostova AT \& Talalay P (2010) NAD(P)H:quinone acceptor oxidoreductase 1 (NQO1), a multifunctional antioxidant enzyme and exceptionally versatile cytoprotector. Arch Biochem Biophys 501, 116-123.

43. Decker M, Arand M \& Cronin A (2009) Mammalian epoxide hydrolases in xenobiotic metabolism and signaling. Arch Toxicol 83, 297-318.

44. Penning TM \& Drury JE (2007) Human aldo-keto reductases: function, gene regulation, and single nucleotide polymorphisms. Arch Biochem Biophys 464, 241-250.

45. Ellis EM, Judah DJ, Neal GE, et al. (1993) An ethoxyquininducible aldehyde reductase from rat liver that metabolizes aflatoxin B1 defines a subfamily of aldo-keto reductases. Proc Natl Acad Sci U S A 90, 10350-10354.

46. Ellis EM, Judah DJ, Neal GE, et al. (1996) Regulation of carbonyl-reducing enzymes in rat liver by chemoprotectors. Cancer Res 56, 2758-2766.

47. Kelly VP, Ellis EM, Manson MM, et al. (2000) Chemoprevention of aflatoxin B1 hepatocarcinogenesis by coumarin, a natural benzopyrone that is a potent inducer of aflatoxin B1-aldehyde reductase, the glutathione $S$-transferase A5 and P1 subunits, and NAD(P)H:quinone oxidoreductase in rat liver. Cancer Res 60, 957-969.

48. Wanichwatanadecha P, Sirisrimangkorn S, Kaewprag J, et al. (2012) Transactivation activity of human papillomavirus type 16 E6*I on aldo-keto reductase genes enhances chemoresistance in cervical cancer cells. J Gen Virol 93, 1081-1092.

49. Jin Y, Mesaros AC, Blair IA, et al. (2011) Stereospecific reduction of $5 \beta$-reduced steroids by human ketosteroid reductases of the AKR (aldo-keto reductase) superfamily: role of AKR1C1-AKR1C4 in the metabolism of testosterone and progesterone via the $5 \beta$-reductase pathway. Biochem $J$ 437, 53-61.

50. Chen M, Drury JE \& Penning TM (2011) Substrate specificity and inhibitor analyses of human steroid $5 \beta$-reductase (AKR1D1). Steroids 76, 484-490.

51. Shultz CA, Quinn AM, Park JH, et al. (2011) Specificity of human aldo-keto reductases, NAD(P)H:quinone oxidoreductase, and carbonyl reductases to redox-cycle polycyclic aromatic hydrocarbon diones and 4-hydroxyequilenin-oquinone. Chem Res Toxicol 24, 2153-2166.

52. Satoh T \& Hosokawa M (2006) Structure, function and regulation of carboxylesterases. Chem Biol Interact $\mathbf{1 6 2}$ 195-211.

53. Primiano T, Egner PA, Sutter TR, et al. (1995) Intermittent dosing with oltipraz: relationship between chemoprevention of aflatoxin-induced tumorigenesis and induction of glutathione S-transferases. Cancer Res 55, 4319-4324.

54. Josephy PD (2010) Genetic variations in human glutathione transferase enzymes: significance for pharmacology and toxicology. Hum Genomics Proteomics 2010, 876940.

55. Coggan M, Flanagan JU, Parker MW, et al. (2002) Identification and characterization of GSTT3, a third murine Theta class glutathione transferase. Biochem J 366, 323-332.

56. Luo W, Kinsey M, Schiffman JD, et al. (2011) Glutathione $S$-transferases in pediatric cancer. Front Oncol 1, 39.

57. Beebe-Dimmer JL, Iyer PT, Nriagu JO, et al. (2012) Genetic variation in glutathione $S$-transferase omega-1, arsenic methyltransferase and methylene-tetrahydrofolate reductase, arsenic exposure and bladder cancer: a case-control study. Environ Health 11, 43.

58. Gamage N, Barnett A, Hempel N, et al. (2006) Human sulfotransferases and their role in chemical metabolism. Toxicol Sci 90, 5-22.

59. Bock KW (2010) Functions and transcriptional regulation of adult human hepatic UDP-glucuronosyl-transferases (UGTs): mechanisms responsible for interindividual variation of UGT levels. Biochem Pharmacol 80, 771-777.

60. Dean M, Hamon Y \& Chimini G (2001) The human ATPbinding cassette (ABC) transporter superfamily. J Lipid Res 42, 1007-1017.

61. Suh JH, Shenvi SV, Dixon BM, et al. (2004) Decline in transcriptional activity of Nrf2 causes age-related loss of glutathione synthesis, which is reversible with lipoic acid. Proc Natl Acad Sci U S A 101, 3381-3386.

62. Wu ML, Ho YC, Lin CY, et al. (2011) Heme oxygenase-1 in inflammation and cardiovascular disease. Am J Cardiovasc Dis 1, 150-158.

63. Jung TS, Kim SK, Shin HJ, et al. (2012) $\alpha$-Lipoic acid prevents non-alcoholic fatty liver disease in OLETF rats. Liver Int $\mathbf{3 2}$ 1565-1573.

64. Castro MC, Massa ML, Schinella G, et al. (2013) Lipoic acid prevents liver metabolic changes induced by administration of a fructose-rich diet. Biochim Biophys Acta 1830, $2226-2232$. 
65. Klaassen CD \& Reisman SA (2010) Nrf2 the rescue: effects of the antioxidative/electrophilic response on the liver. Toxicol Appl Pharmacol 244, 57-65.

66. Vomhof-Dekrey EE \& Picklo MJ Sr (2012) The Nrf2-antioxidant response element pathway: a target for regulating energy metabolism. J Nutr Biochem 23, 1201-1206.

67. Finlay LA, Michels AJ, Butler JA, et al. (2012) R- $\alpha$-lipoic acid does not reverse hepatic inflammation of aging, but lowers lipid anabolism, while accentuating circadian rhythm transcript profiles. Am J Physiol Regul Integr Comp Physiol 302, R587-R597.

68. Whitton C, Nicholson SK, Roberts C, et al. (2011) National Diet and Nutrition Survey: UK food consumption and nutrient intakes from the first year of the rolling programme and comparisons with previous surveys. Br J Nutr 106, 1899-1914.

69. Kim MS, Park JY, Namkoong C, et al. (2004) Antiobesity effects of $\alpha$-lipoic acid mediated by suppression of hypothalamic AMP-activated protein kinase. Nat Med 10, $727-733$.

70. Wang Y, Li X, Guo Y, et al. (2010) $\alpha$-Lipoic acid increases energy expenditure by enhancing adenosine monophosphate-activated protein kinase-peroxisome proliferatoractivated receptor- $\gamma$ coactivator- $1 \alpha$ signaling in the skeletal muscle of aged mice. Metabolism 59, 967-976.

71. Prieto-Hontoria PL, Pérez-Matute P, Fernández-Galilea M, et al. (2009) Lipoic acid prevents body weight gain induced by a high fat diet in rats: effects on intestinal sugar transport. J Physiol Biochem 65, 43-50.

72. Peter G \& Borbe HO (1995) Absorption of $\left[7,8^{-14} \mathrm{C}\right] \mathrm{rac}$ $\alpha$-lipoic acid from in situ ligated segments of the gastrointestinal tract of the rat. Arzneimittelforschung 45, 293-299.

73. Schwartz L, Guais A, Israël M, et al. (2013) Tumor regression with a combination of drugs interfering with the tumor metabolism: efficacy of hydroxycitrate, lipoic acid and capsaicin. Invest New Drugs 31, 256-264. 